\title{
The role of vision-related problems in fatal road accidents in Finland
}

\section{Wedenoja, Juho}

2021

Wedenoja , J , Kalsi , J , Salenius , S , Parkkari , K, Kaarniranta , K \& Tervo , T 2021, ' The role of vision-related problems in fatal road accidents in Finland ' , Acta Ophthalmologica, vol. 99 , no. 4 , pp. 427-430 . https://doi.org/10.1111/aos.14616

http://hdl.handle.net/10138/339489

https://doi.org/10.1111/aos.14616

acceptedVersion

Downloaded from Helda, University of Helsinki institutional repository.

This is an electronic reprint of the original article.

This reprint may differ from the original in pagination and typographic detail.

Please cite the original version. 


\section{The role of vision related problems in fatal road accidents in Finland}

Juho Wedenoja ${ }^{1}$, Juhani Kalsi ${ }^{2}$, Salla Salenius ${ }^{3}$, Kalle Parkkari ${ }^{3}$, Kai Kaarniranta ${ }^{2}$, Timo Tervo ${ }^{4}$

1. Department of Ophthalmology, University of Helsinki and Helsinki University Hospital, Helsinki, Finland.

2. Department of Ophthalmology, University of Eastern Finland and Kuopio University Hospital, Kuopio, Finland.

3. The Finnish Crash Data Institute (OTI), Helsinki, Finland.

4. Institute of Clinical Medicine, Department of Ophthalmology and Otorhinolaryngology, University of Helsinki, Helsinki, Finland. 


\section{SYNOPSIS}

While observational failures are a leading cause of fatal motor vehicle accidents in Finland, eye-originating vision problems are rarely a causative risk. Making current visual standards more stringent would unlikely to be effective in fatal motor vehicle accident prevention.

\section{ABSTRACT}

PURPOSE: To evaluate the significance of vision related problems in fatal motor vehicle accidents (FMVAs) based on a systematic investigation process by multidisciplinary Road Accident Investigation Teams (RAITs).

METHODS: Retrospective registry-based study of all FMVAs during the years 2012-2016 in Finland in which driver causing the accident had a valid Finnish driving license and the operated motor vehicle required having a driving license.

RESULTS: There were a total of 968 FMVAs. In only $1.3 \%$ of all the accidents a vision related problem was considered to have contributed to the FMVA, while an observational failure of $23.6 \%$ was the leading cause of all the FMVAs.

CONCLUSIONS: Eye-originating vision problems are rarely a causative risk for FMVAs in Finland. Making current visual standards more stringent would unlikely to be effective in FMVA prevention. 


\section{INTRODUCTION}

Sufficient vision is a crucial component of driving fitness. In the European Union (EU), the visual standards are defined in the Medical Annex of the 2009/113/EC directive (eur-lex.europa.eu). However, the national standards vary even between the Nordic countries (Bro \& Lindblom 2018). Tests for visual acuity and visual field as well as color vision are standardized, in contrast to those evaluating twilight vision and contrast sensitivity. Visual acuity is generally the only parameter which is systematically tested. The visual field testing has been carried out only in conjunction with follow-up of an eye disease or an anomalous clinical test finding. The practical testing of non-standardized parameters is often difficult to interpret or may lead to legislative conflicts.

Since the 1960s, visual acuity has been systematically screened as a traffic accident risk and in the analysis of driver safety or driver performance (Burg 1966). Despite the rigorous testing criteria, it is controversial whether there is any association between visual acuity screening and motor vehicle accidents (Owsley \& McGwin 2010). It has been claimed that regular vision screening possibly only reduces the accident risk among elderly drivers (McGwin et al. 2008). Additionally, the incidence of poor visual acuity as a causative factor for fatal motor vehicle accidents (FMVAs) remains undetermined. In Finland, the current law demands that the driving fitness should be estimated at five year intervals once the driver is older than 70 years of age. If the driving fitness criteria are not met, physicians are required by law to submit an official notification to the police (Finnish Transport and Communications Agency Traficom 2019). Most of these notifications are submitted by ophthalmologists (Löytty 2015).

The Finnish national law (1512/2016, www.finlex.fi) states that all road and off-road traffic accidents should be investigated independently and in-depth by Road Accident Investigation Teams (RAITs) according to an annual investigation plan drafted by the Finnish Motor Insurers' Centre. Since 1997, the investigation plan has involved all fatal accidents where notification has been received early enough to start an investigation within three days from the accident. Each RAIT conducts investigations independently of the other RAITs. They are not directly connected to the juridical system and they do not decide on guilt or insurance compensations. Each RAIT consists of delegates from the police force, road specialists, vehicle engineering specialists, physicians, and behavioral scientists.

According to the standardized VALT investigation method used by RAITs, the origin of the accident is described using the following terms: key event, immediate risk factors, and background risk factors (Finnish Motor Insurers' Centre 2004). All the RAIT team members take part in the evaluation of the accident and on the definition of risk factors. Only one immediate risk factor, which has made the accident unavoidable, is determined for an accident event if it can be identified by the RAIT. In addition, all accidents are analyzed to identify all immediate and contributory risk factors. The subsequently devised and proposed common European accident investigation method DaCoTA has a similar structure with respect to the combination of different data variables and expert analysis (Thomas et al. 2013). The Finnish Crash Data Institute OTI (www.oti.fi) is an independent unit within the Finnish Motor Insurers' Centre. It coordinates the RAITs' activities, is responsible for training the investigators, and maintains a registry of RAIT road accident data, which is openly available for research. Additionally, this data is not censored in any way, for example by leaving out suicides (Eurostat 2010). In this study, we determined the role of vision related problems contributing to all FMVAs during the years 2012-2016 in Finland by utilizing this comprehensive RAIT data from the OTI registry.

\section{MATERIALS AND METHODS}

The study data comprises RAIT data of all FMVAs during the five-year period of 2012-2016 in Finland. The analysis involved accidents in which driver causing the accident had a valid Finnish driving license and the 
operated motor vehicle required having a driving license. The other accident party could be another motor vehicle, bicycle, pedestrian, or an animal.

All the FMVAs were screened if there was information of any eye or vision related problem of the driver, in which cases all the RAIT data were further examined for detailed information on the driver's vision specially to determine if this could have exerted an influence on the FMVA. One task of the RAIT physician member is to collect all relevant health data from the patient registries from diverse health care sources into investigation forms as required by legislation. Additionally, close relatives are routinely interviewed for known health problems by police officials and/or RAIT members. This allows multiple ways to detect any known or suspected vision related problem of the driver by both police and/or RAIT.

\section{RESULTS}

During the years of 2012-2016, there were 968 FMVAs involving cases where the driver had a valid Finnish driving license. The two largest immediate risk categories were observational failures (for example, failures to observe the other party or the traffic situation) in $23.6 \%$, and deliberate or willful acts (for example, intentional suicides) in $16.2 \%$ of these fatal crashes (Table 1 ).

Any vision related condition was assessed as an immediate risk in none of these FMVAs, but for a total of 35 drivers, there was database information on or a suspicion of an eye disorder, vision defect and/or some problem related to vision. After an examination of all the RAIT data of these cases, a significant majority of them (22 out of 35 ) were discarded since the indicated eye or vision condition had exerted no effect on the FMVA (attack of illness not related to vision, 5 cases; intentional action or suicide, 4 cases; falling asleep, 3 cases), there actually was no true vision defect at all (vision adequately corrected with spectacles which were in use, 5 cases; performed cataract surgery with good postoperative vision, 2 cases; vision related symptom or suspicion in the past without documentation of any current condition, 2 cases), or the driver had already been banned from driving due to a health condition but did not obey this prohibition (1 case).

Thus, according to collected medical record information by the RAIT physician member, a total of 13 drivers had an eye and/or vision related problem, which could be considered to have contributed to the FMVA (Table 2). Of these, 5 were included in the observational failure risk group, number of which did not differ significantly from the rest of the FMVAs according to Fisher exact test. In 4 of the cases, it is unclear if the driving standards had been truly met in preceding health care contacts based on the health care record information; these are marked with an asterisk $(*)$. 


\section{DISCUSSION}

Our comprehensive Finnish RAIT data demonstrates that a direct vision related problem of the driver is very rarely directly either an immediate or background risk factor in an FMVA, a finding that is in line with previous studies (Owsley et al. 1998, Owsley et al. 2001, Tervo et al. 2013, Tervo et al. 2008). In the years that this study covers, there was not a single accident in Finland, in which a vision related condition had been assessed as an immediate risk, and in only $1.3 \%$ of all the FMVAs, could it be considered as a background risk. Hence, the vast majority of FMVAs are not due to any eye disease or vision disturbances and therefore should not be preventable if there were more stringent vision screening (Owsley \& McGwin 1999, Owsley \& McGwin 2010). Interestingly, while being the largest main risk category, observational failures seem to be very infrequently related to any vision related problem, further supported by that these problems are not overrepresented in this risk category.

Our data examined only motor vehicle accidents causing a loss of life and it does not analyze factors underlying non-fatal accidents. However, the prevention of FMVAs should be naturally the top priority regarding road safety, and actions aimed at FMVA reduction would presumably also lead to a reduction in non-fatal accidents. Although national features related to, for example, road system, speed limits, average motor vehicle age, and legislation related to alcohol and other psychoactive substance use may impact on the specific features of the FMVAs, overall this data should be generalizable. Additionally, it could be argued that in countries with more strict regulations the amount of vision related problems in FMVAs should be even lower (Bro \& Lindblom 2018). However, this kind of study requires data of FMVAs which are not available in a large number of countries.

Several factors may impact on the estimation of whether vision has been involved in a FMVA. First, the driver health data available to the RAIT physician member may not always include a recent assessment of visual acuity, visual field, or general eye related data. This kind of data is available for drivers of 70 years of age or older or drivers whose driving license is less than five years old (Löytty 2015). The lack of this data does not necessarily mean that the driver really did not have a vision related problem, since an individual's eye health examination may have been only conducted in the private sector or possible symptoms may have been missed or not examined at all. Secondly, an autopsy examination may reveal an existing eye or vision related problems only if they have been particularly sought, such as cataract. Thirdly, driver selfregulation as a protective factor may diminish vision related risks better than other somatic condition related risks. Drivers with failing visual functions (for instance, poor visual acuity or contrast sensitivity) tend to modify their driving habits by reducing their mileage and favoring better lightning conditions (Agramunt et al. 2016, Freeman et al. 2006). Additionally, vision problems such as an inability to spot dark objects in darkness, rain, or being dazzled by oncoming vehicles may be experienced by people with clinically normal eyes (Owsley 2016).

In Finland, the current law requires physicians to notify police officials if the patient's health status does not meet driving standards and the situation is considered to be permanent or it has continued for at least six months (Bro \& Lindblom 2018, Finnish Transport and Communications Agency Traficom 2019). The assessment of driving fitness is typically vision-oriented, supported by a survey conducted in Southwestern Finland which revealed that more than half of these notifications were made by ophthalmologists (Löytty 2015). Thus, while the current visual standards and screening regulations seem to be overall rather effective in the prevention of FMVAs, our data implies that a large variety of conditions capable of compromising driving capability are currently underreported and possibly even disregarded. Here, sudden disease attacks accounted for $13.9 \%$ of all FMVAs, with falling asleep or becoming unconscious making up additional $6.8 \%$. Interestingly, intentional actions constituted a still greater proportion of all FMVAs than sudden disease attacks, with the majority of these being classified as suicides (de facto, "willingly driving into a situation"). It could be postulated that psychiatric conditions, typically underlying suicidality, form 
one of the largest disease entities predisposing to FMVAs. The importance of a thorough psychical assessment in all patient contacts should not be underestimated (Airaksinen et al. 2016).

In summary, vision related reasons seem to have only a marginal direct impact on fatal traffic accidents, provided that the individuals fully adhere to the current requirement to vision (Finnish Transport and Communications Agency Traficom 2019). The current regulations to control vision seem to be effective in Finland and presumably elsewhere with comparable vision related regulations. Therefore, any tightening of visual standards for driving would be likely an ineffective measure in the prevention of FMVAs. Instead, if one wishes to reduce the number of FMVAs the preventive actions related to health should be targeted on psychiatric conditions as well as somatic disorders that predispose an individual to sudden changes in one's state of health.

\section{ACKNOWLEDGEMENTS}

The authors report no conflicts of interest. 
Table 1. Immediate risk factor top categories (one per every fatal motor vehicle accident) in Finland in years 2012-2016 as identified by road accident investigation teams.

\begin{tabular}{lll}
\hline Immediate risk & $\mathbf{n}$ & $\mathbf{\%}$ \\
\hline Observational failure & 228 & $23.6 \%$ \\
Intentional action & 147 & $15.2 \%$ \\
Attack of illness & 135 & $13.9 \%$ \\
Anticipation mistake & 108 & $11.2 \%$ \\
Faulty steering movement & 96 & $9.9 \%$ \\
Faulty driving path & 70 & $7.2 \%$ \\
Falling asleep or unconscious & 66 & $6.8 \%$ \\
Other vehicle handling mistake & 56 & $5.8 \%$ \\
Driving regardless of known risk & 10 & $1.0 \%$ \\
Sudden change in traffic environment & 10 & $1.0 \%$ \\
Sudden event connected with vehicle & 8 & $0.8 \%$ \\
Participant could not avoid accident & 2 & $0.2 \%$ \\
Other or unclear reason & 32 & $3.3 \%$ \\
\hline Total & 968 & \\
\hline
\end{tabular}


Table 2. Identified eye or vision problems in FMVAs.

\begin{tabular}{|c|c|c|c|c|c|c|}
\hline Year & Accident type & Immediate risk & Deceased & Driver's age & Vision information & Observational failure \\
\hline 2012 & $\begin{array}{l}\text { Hitting another vehicle } \\
\text { in a curve }\end{array}$ & $\begin{array}{l}\text { Insufficient observation } \\
\text { of driver's own position }\end{array}$ & Driver & 65 & $\begin{array}{l}\text { Right eye blind due to previous central artery } \\
\text { occlusion }\end{array}$ & Yes \\
\hline 2012 & $\begin{array}{l}\text { Hitting another vehicle } \\
\text { in a curve }\end{array}$ & Faulty driving path & Other party & 45 & $\begin{array}{l}\text { Left eye nearly blind (Snellen 0.05), right eye } \\
\text { fulfilling passenger car driving criteria without } \\
\text { correction }\end{array}$ & No \\
\hline 2012 & $\begin{array}{l}\text { Hitting another vehicle } \\
\text { while turning left }\end{array}$ & $\begin{array}{l}\text { Failure to observe the } \\
\text { other party }\end{array}$ & Passenger & 83 & $\begin{array}{l}\text { Deteriorated vision (ophthalmologist } \\
\text { examination required every second year) but } \\
\text { vision fulfilling driving criteria without } \\
\text { correction (ophthalmologist examination } 6 \\
\text { months before) }\end{array}$ & Yes \\
\hline 2013 & $\begin{array}{l}\text { Hitting another vehicle } \\
\text { in a curve }\end{array}$ & Faulty driving path & Driver & 81 & $\begin{array}{l}\text { One eye removed decades ago, deteriorated } \\
\text { vision in the other eye with required spectacles } \\
\text { possibly not in use }\end{array}$ & No \\
\hline $2014 *$ & $\begin{array}{l}\text { Turning right in a left } \\
\text { turning maneuver }\end{array}$ & $\begin{array}{l}\text { Faulty steering } \\
\text { movement }\end{array}$ & Driver & 20 & $\begin{array}{l}\text { Small central lower temporal quadrant visual } \\
\text { field defect, double vision and left eye } \\
\text { mydriasis due to left oculomotor nerve palsy, } \\
\text { left hemiparesis with frontotemporal and basal } \\
\text { CNS defects and neuropsychological symptoms }\end{array}$ & No \\
\hline $2014 *$ & $\begin{array}{l}\text { Rear-end collision with } \\
\text { a pedestrian }\end{array}$ & Attack of illness & Other party & 53 & $\begin{array}{l}\text { Deteriorated vision due to optic neuropathy } \\
\text { resulting from alcoholism, lacking the required } \\
\text { police official notification of the health status }\end{array}$ & No \\
\hline $2014 *$ & $\begin{array}{l}\text { Hitting another vehicle } \\
\text { in a curve }\end{array}$ & Faulty driving path & Driver & 56 & $\begin{array}{l}\text { Right eye removed due to ocular melanoma } 7 \\
\text { months prior accident, problems staying in lane } \\
\text { while driving }\end{array}$ & No \\
\hline $2014 *$ & $\begin{array}{l}\text { Hitting a pedestrian on } \\
\text { a crosswalk }\end{array}$ & $\begin{array}{l}\text { Failure to observe the } \\
\text { other party }\end{array}$ & Other party & 69 & $\begin{array}{l}\text { Homonym left upper quadrant anopsia } \\
\text { (previously fulfilling driving criteria, but with no } \\
\text { recent estimation) }\end{array}$ & Yes \\
\hline
\end{tabular}


2014 Rear-end collision with a cyclist

Failure to observe the other party (as well as passenger warning)

Turning right in a left turning curve

\section{Hitting another vehicle} in a curve

Faulty driving path

Faulty driving path

Driver

Driver

Failure to observe the other party

Other party

73

2016 ing another while crossing traffic
Deteriorated vision (with spectacles in use) and deteriorated hearing (with designated hearing aid not in use)

Deteriorated vision in right eye and dazzled by on-coming lights

Deteriorated vision (exact visual acuity not known), dazzled by on-coming lights

Several diseases and medications affecting driving ability, including cataract (visual acuity not known) and Parkinson's disease 


\section{REFERENCES}

Agramunt S, Meuleners LB, Fraser ML, Morlet N, Chow KC \& Ng JQ (2016): Bilateral cataract, crash risk, driving performance, and self-regulation practices among older drivers. J Cataract Refract Surg 42: 788-794.

Airaksinen N, Korpinen A \& Parkkari I (2016): Tie- ja raideliikenteen itsemurhat Esiselvitys. Finland: Trafi Research Reports.

Bro T \& Lindblom B (2018): Strain out a gnat and swallow a camel? - vision and driving in the Nordic countries. Acta Ophthalmol 96: 623-630.

Burg A (1966): Visual acuity as measured by dynamic and static tests: a comparative evaluation. J Appl Psychol 50: 460-466.

Eurostat, ITF \& UNECE (2010): Illustrated Glossary for Transport Statistics, 4th Edition. Luxembourg: Publications Office of the European Union.

Finnish Motor Insurers' Centre (2004): VALT-Method 2003. Finland: Finnish Motor Insurers' Centre.

Finnish Transport and Communications Agency Traficom (2019): Fitness to drive - Guidelines for healthcare professionals. Finland: Finnish Transport and Communications Agency Traficom.

Freeman EE, Munoz B, Turano KA \& West SK (2006): Measures of visual function and their association with driving modification in older adults. Invest Ophthalmol Vis Sci 47: 514-520.

Löytty M (2015): Ajo-oikeuden hakijoiden, haltijoiden ja uusijoiden terveysvaatimusten täyttymisen varmistamisen käytännöt Euroopassa. Finland: Trafi Publications 15.

McGwin G Jr, Sarrels SA, Griffin R, Owsley C \& Rue LW 3rd (2008): The impact of a vision screening law on older driver fatality rates. Arch Ophthalmol 126: 1544-1547.

Owsley C (2016): Vision and Aging. Annu Rev Vis Sci 2: 255-271.

Owsley C \& McGwin G Jr (2010): Vision and driving. Vision Res 50: 2348-2361.

Owsley C \& McGwin G Jr (1999): Vision impairment and driving. Surv Ophthalmol 43: 535-550.

Owsley C, McGwin G Jr \& Ball K (1998): Vision impairment, eye disease, and injurious motor vehicle crashes in the elderly. Ophthalmic Epidemiol 5: 101-113.

Owsley C, Stalvey BT, Wells J, Sloane ME \& McGwin G Jr (2001): Visual risk factors for crash involvement in older drivers with cataract. Arch Ophthalmol 119: 881-887.

Tervo T, Raty E, Sulander P, Holopainen JM, Jaakkola T \& Parkkari K (2013): Sudden death at the wheel due to a disease attack. Traffic Inj Prev 14: 138-144.

Tervo TM, Neira W, Kivioja A, Sulander P, Parkkari K \& Holopainen JM (2008): Observational failures/distraction and disease attack/incapacity as cause(s) of fatal road crashes in Finland. Traffic Inj Prev 9: 211-216.

Thomas P, Muhlrad N, Hill J, Yannis G, Dupont E, Martensen H, Hermitte T \& Bos N (2013): Final Project Report, Deliverable 0.1 of the EC FP7 project DaCoTA. 